Supplement of Nat. Hazards Earth Syst. Sci., 16, 1401-1411, 2016

http://www.nat-hazards-earth-syst-sci.net/16/1401/2016/

doi:10.5194/nhess-16-1401-2016-supplement

(C) Author(s) 2016. CC Attribution 3.0 License.

(c) (1)

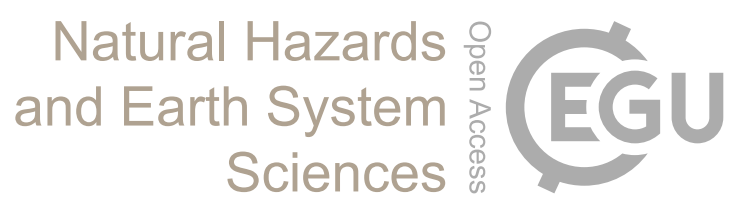

Supplement of

\title{
Modelling the socio-economic impact of river floods in Europe
}

L. Alfieri et al.

Correspondence to: Lorenzo Alfieri (lorenzo.alfieri@jrc.ec.europa.eu)

The copyright of individual parts of the supplement might differ from the CC-BY 3.0 licence. 


\section{Liflood calibration performance}

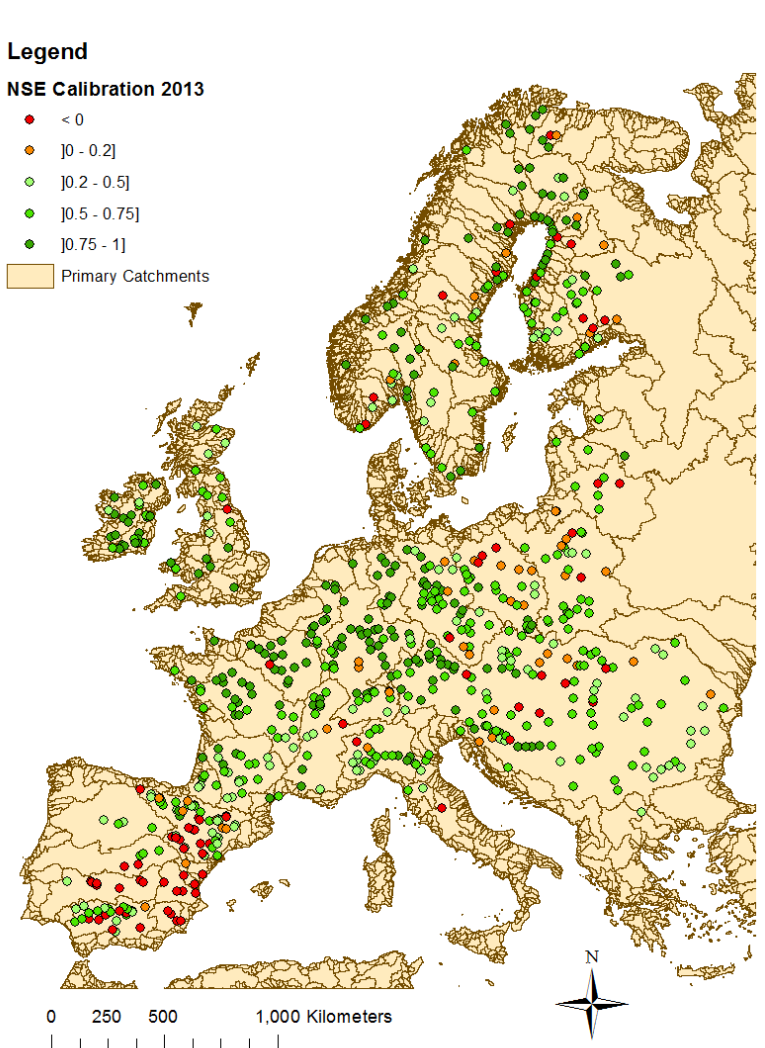

Legend

NSE Validation 2013

not validated

- $<0$

] $] 0-0.2]$

- $0.2-0.5]$

- $] 0.5-0.75]$

- $10.75-1]$

Primary Catchment

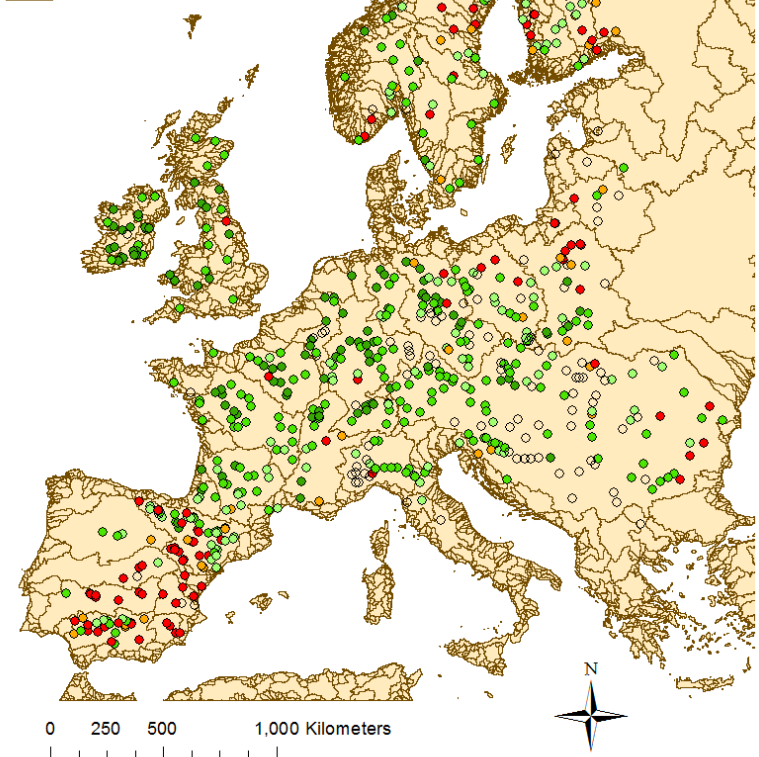

Figure S1: Nash-Sutcliffe Efficiency of the calibrated stations for the calibration (1994-2002, left) and the validation period (2003-2012, right).

Table S1: Number of calibrated stations divided by classes of Nash-Sutcliffe Efficiency.

\begin{tabular}{ccc}
\hline $\begin{array}{c}\text { Number of } \\
\text { stations }\end{array}$ & Calibration & Validation \\
\hline Total & 693 & 594 \\
NSE $<0$ & $72(10 \%)$ & $97(16 \%)$ \\
NSE $>=0$ & $621(90 \%)$ & $497(84 \%)$ \\
NSE $>0.2$ & $578(83 \%)$ & $461(78 \%)$ \\
NSE $>0.5$ & $463(67 \%)$ & $345(58 \%)$ \\
NSE $>0.75$ & $224(32 \%)$ & $123(21 \%)$ \\
\hline
\end{tabular}




\section{Simulated flood inundation maps}
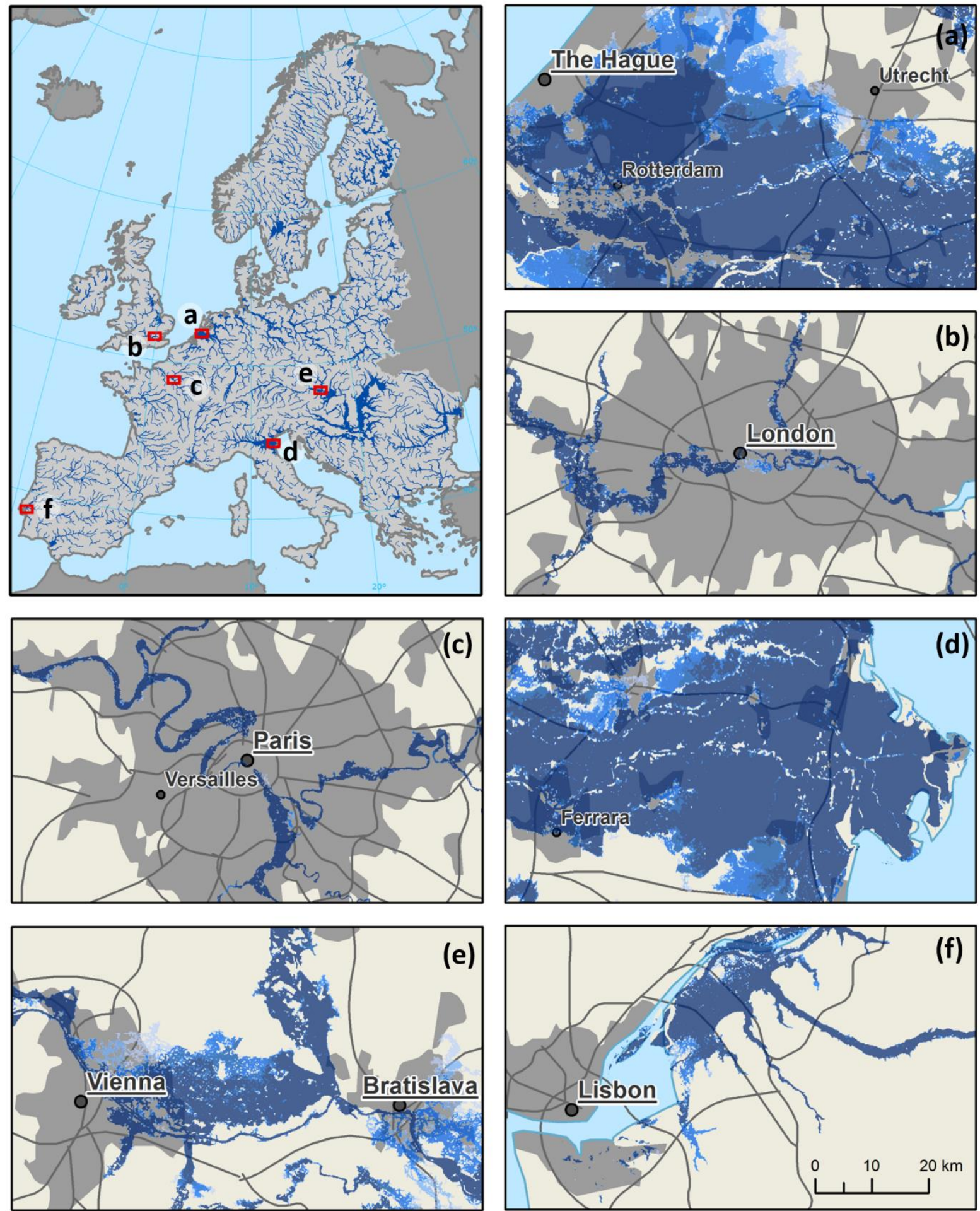

$10 \quad 20 \quad 50 \quad 100 \quad 200 \quad 500 \quad$ T [years]

Figure S2: European flood hazard map for the 500-year return period (main panel) and zoom into six sample regions. The six panels (a-f) include an overlay of the six flood hazard maps with return period (T) of 10, 20, 50, 100, 200, and 500 years. Relatively small differences in the simulated flood extent for different return periods is due to the absence of flood protections in the simulation approach. 


\section{Floods in Central Europe in June 2013}

Lisflood simulations driven by the EFAS-Meteo dataset as input were performed on the European domain and simulated daily discharge was compared with observations in 28 river stations where streamflow data was made available (see Figure S3). Note that some recorded discharge time series include missing values, particularly in the range of extreme values, often due to power cuts following the severe weather and the damaging of the measuring devices caused by the rage of the flood flow. The comparison between simulated and observed discharges is performed for the May-June 2013 time span and is shown in Figure S4. Six relevant skill scores are calculated for the comparison shown in Figure $\mathrm{S} 4$ and are plotted in Figure $\mathrm{S} 5$ as a function of the upstream area of each river gauge. These include (from top-left in Figure S5) the Root Mean Square Error (RMSE) $\left[\mathrm{m}^{3} / \mathrm{s}\right]$, the Normalized Root Mean Square Error (NRMSE), the Percent Bias (PBIAS), the Nash-Sutcliffe Efficiency (NSE), the Pearson Correlation coefficient ( $r$ ), and the Coefficient of Determination (R2).

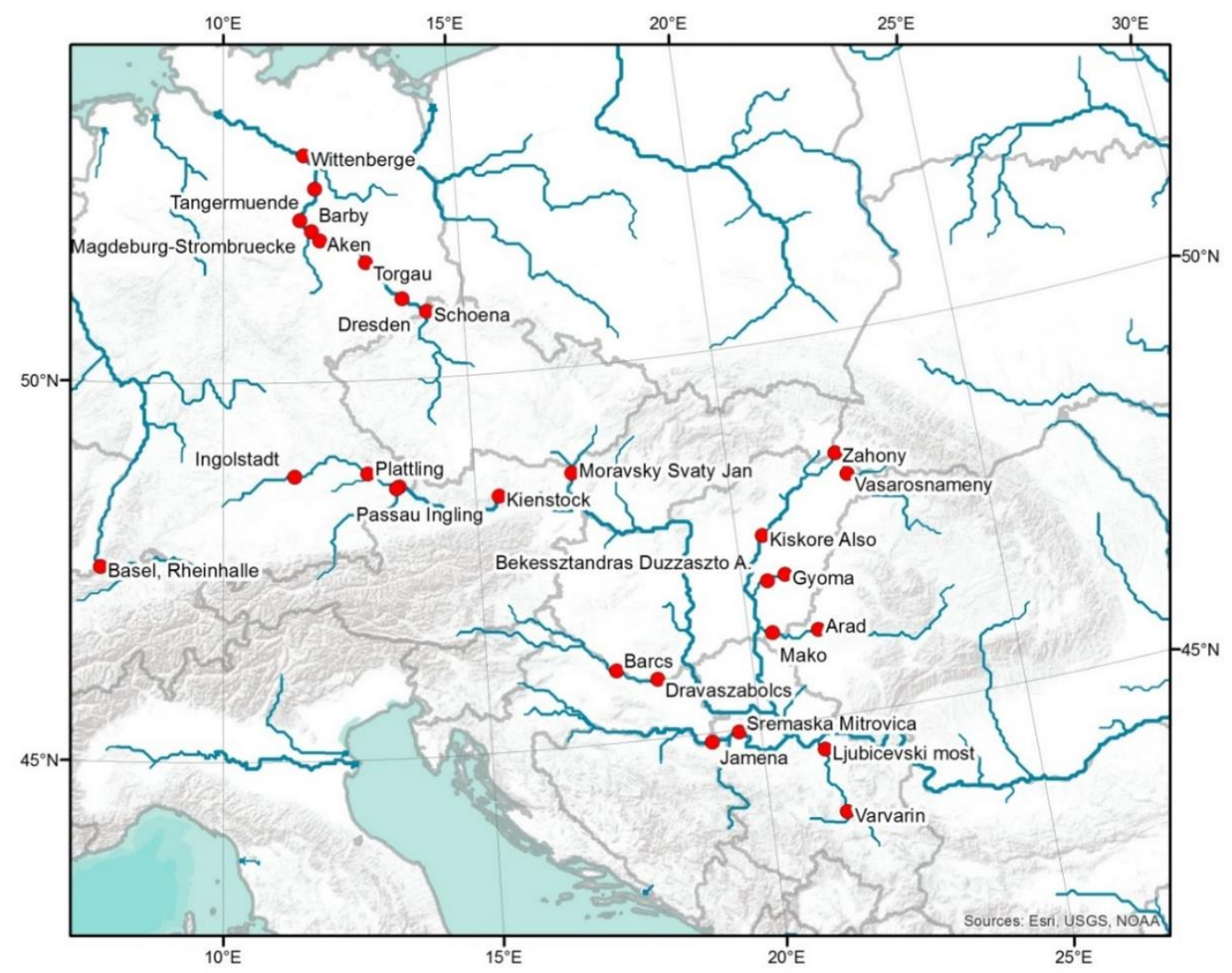

Figure S3: Location of the river gauges where observed daily discharge was provided for May-June 2013. 

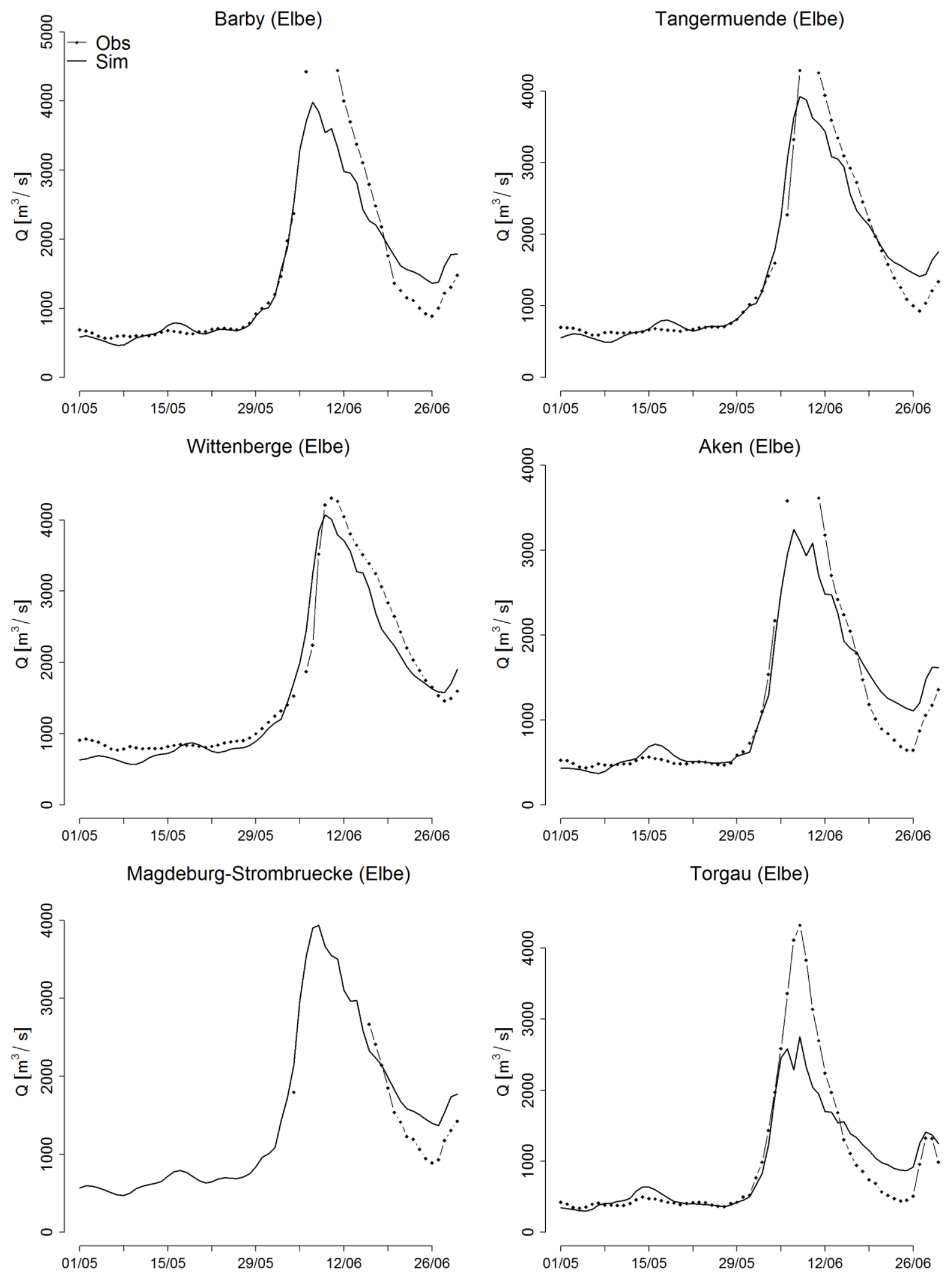

Figure S4: Observed vs. simulated discharges for river gauges shown in Figure S3. 


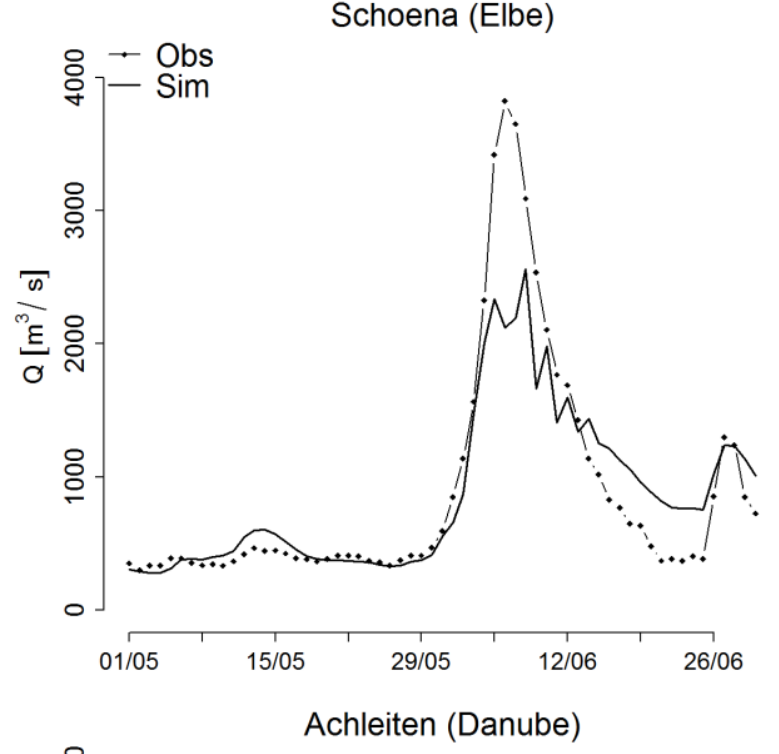

Dresden (Elbe)
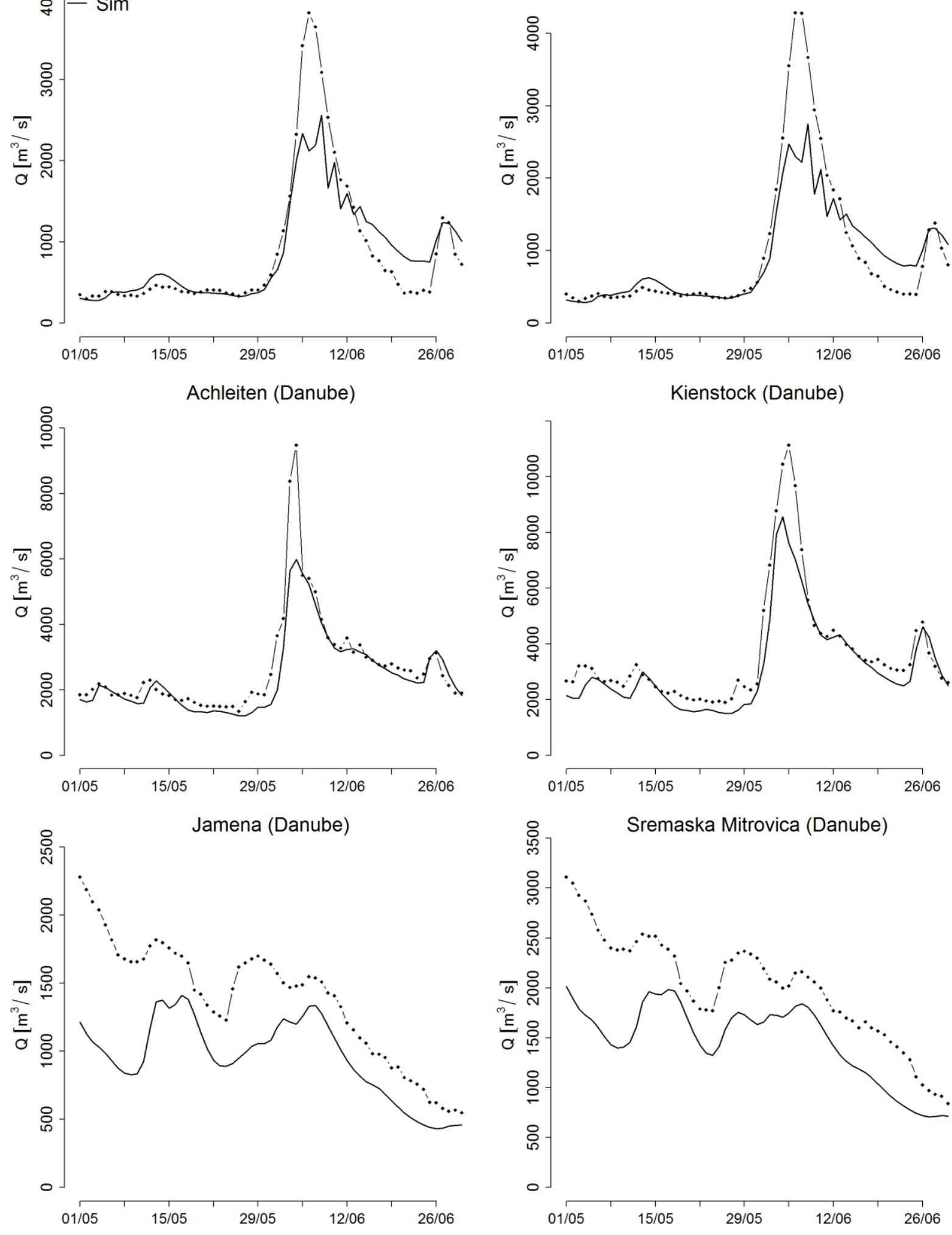

Figure S3 (continued) 

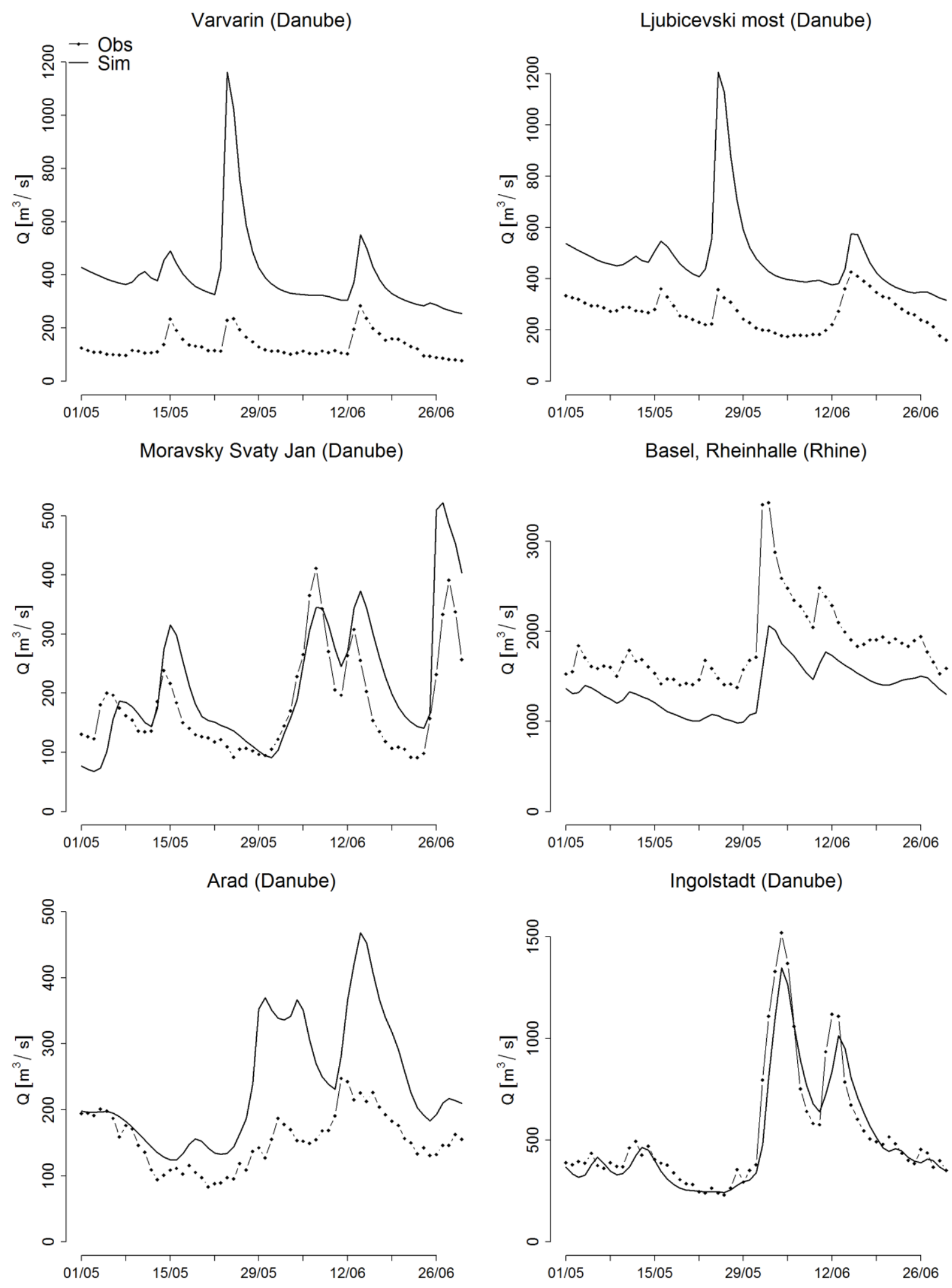

Figure S3 (continued) 

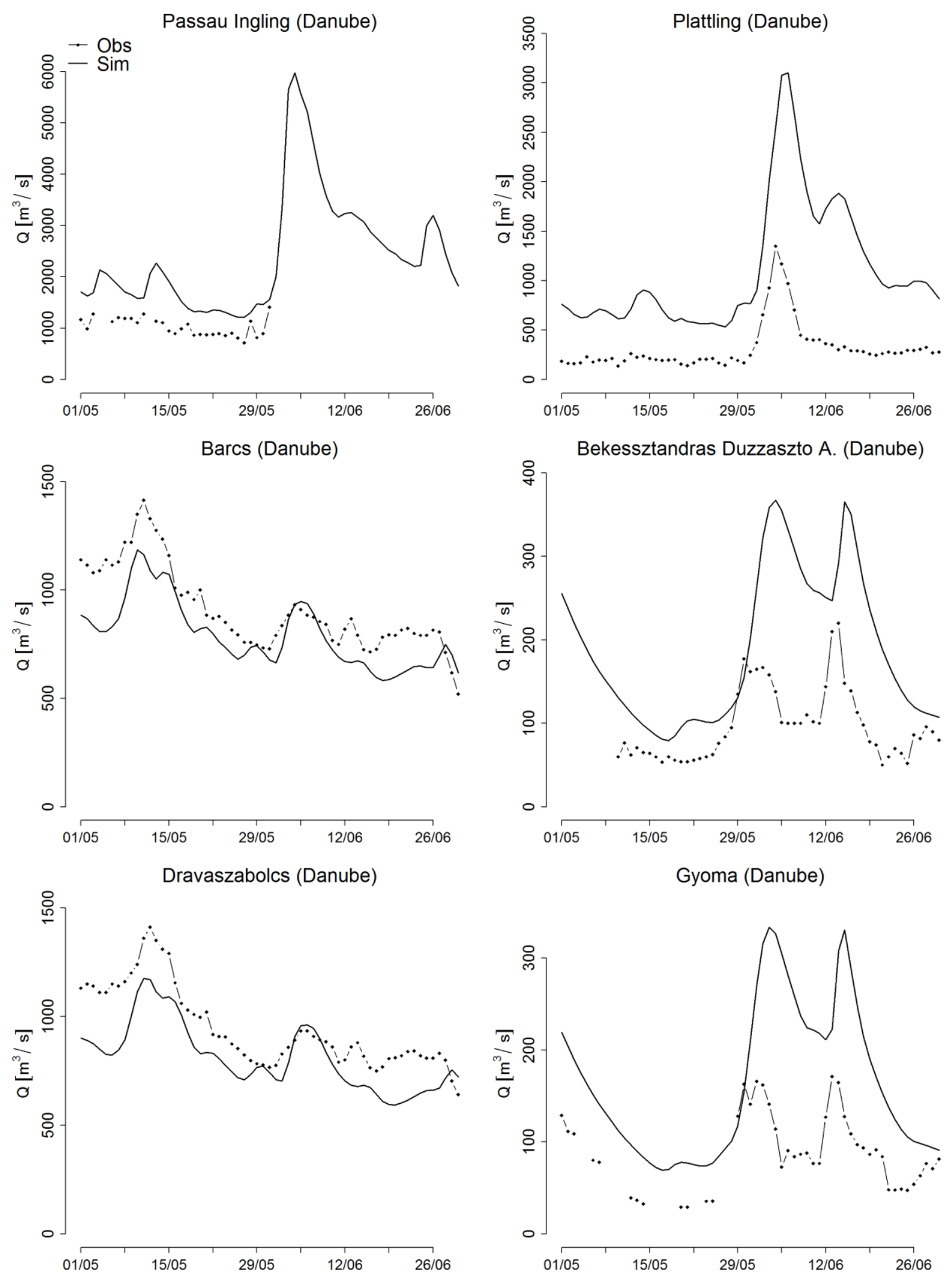

Figure S3 (continued) 

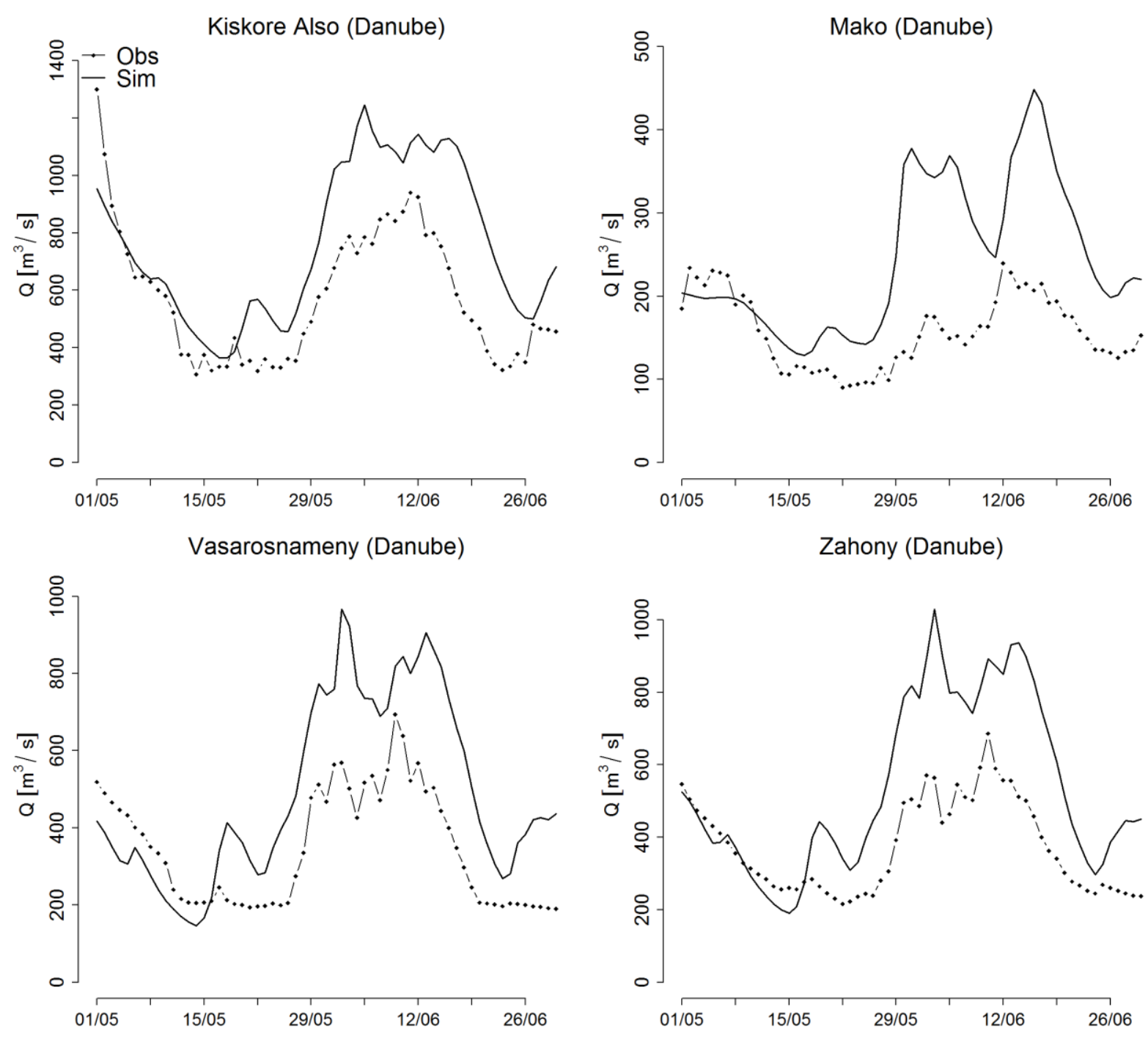

Figure S3 (continued)

Figure S5 shows a general improvement of the simulation performance for increasing upstream area, both in terms of bias and of correlation. Note that no data assimilation of discharge measurements is included in the hydrological model, as initial conditions are always estimated by updating the water balance in the river network, using the model states of the previous day and the maps of observed meteorological variables. In a number of cases the simulated discharge is in good agreement with observations for low flow conditions, while large negative bias occurs for peak discharge values. This points out the limitations given by the space and time resolution of the hydrological model and of the meteorological input data, which limits the representation of extreme discharge peaks, particularly when the event dynamics have peculiar features at finer scales than those considered in the modeling. Indeed, such an issue is less evident on river points further downstream the river network, where the simulation of discharges on average improves. 

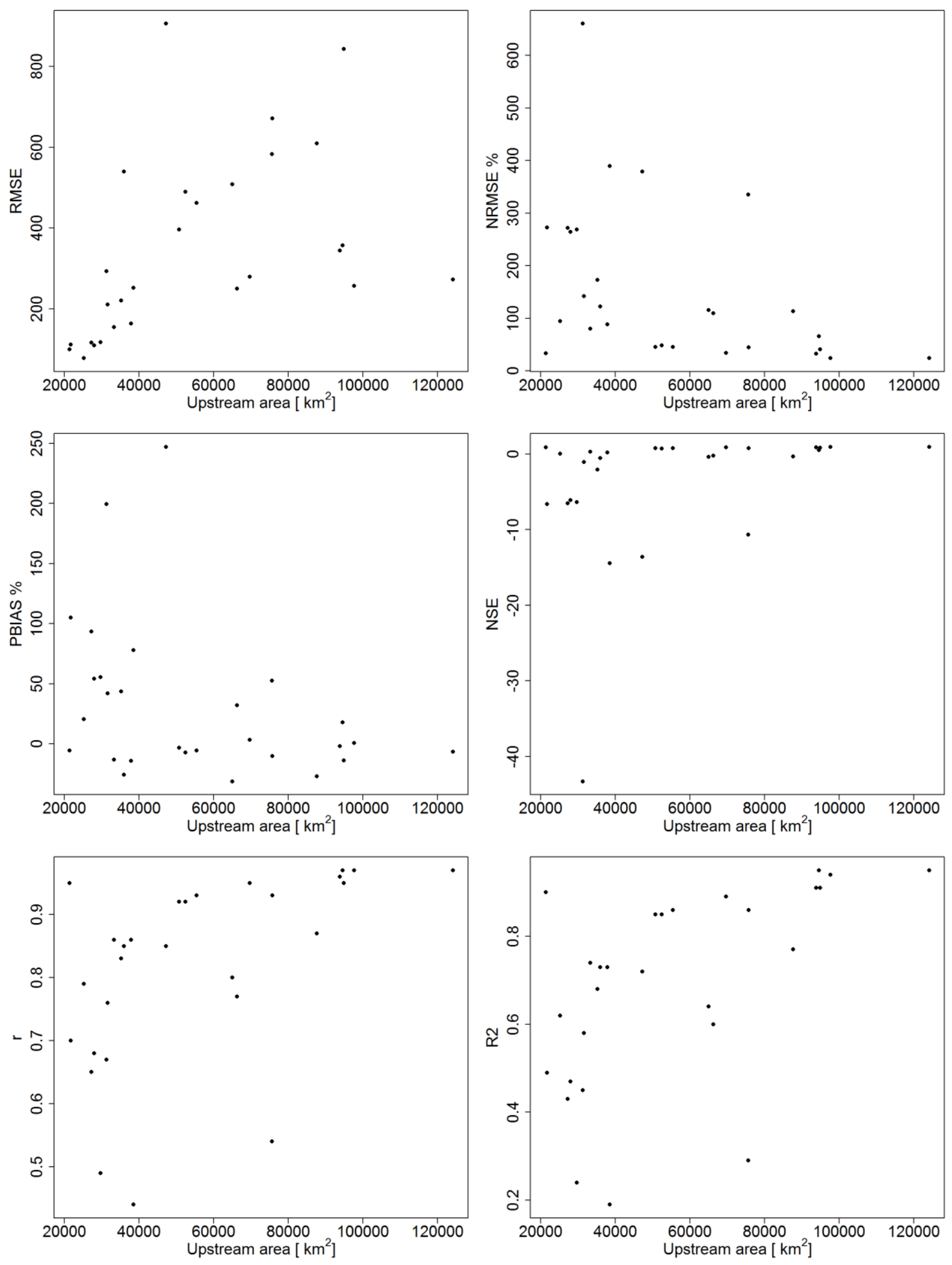

Figure S5: Skill scores of the discharge comparison shown in Figure S4. 
Table S2: 2-digit ISO country code of the considered countries.

\begin{tabular}{ll}
\hline & \\
& Country \\
& \\
\hline Austria & AT \\
Belgium & BE \\
Bulgaria & BG \\
Croatia & HR \\
Czech Republic & CZ \\
Denmark & DK \\
Estonia & EE \\
Finland & FI \\
France & FR \\
Republic of Macedonia & MK \\
Germany & DE \\
Greece & EL \\
Hungary & HU \\
Ireland & IE \\
Italy & IT \\
Latvia & LV \\
Lithuania & LT \\
Luxembourg & LU \\
Netherlands & NL \\
Norway & NO \\
Poland & PL \\
Portugal & PT \\
Romania & RO \\
Slovakia & SK \\
Slovenia & SI \\
Spain & ES \\
Sweden & SE \\
United Kingdom & UK \\
\hline & \\
\hline & \\
\hline
\end{tabular}

